\title{
Minimum income schemes in Europe: is there a trade-off with activation policies?

\author{
Roberto lacono(1)
}

Correspondence:

roberto.iacono@ntnu.no

Department of Applied Social

Science, Norwegian University of

Science and Technology (NTNU),

7491 Trondheim, Norway

\begin{abstract}
This paper makes two contributions to the literature. First, by employing a macrolevel institutional dataset on benefit levels for social assistance (SA) and minimum income protection (MIP) in 22 European countries in the period 1990-2013, I show that the adequacy of income support for low-income inactive individuals in European welfare states has been steadily decreasing since 1994. Second, the paper revisits empirically the hypothesis of a trade-off between the adequacy of out-ofwork benefits and the public expenditure on active labor market policies (ALMPs). The empirical results of the fixed effects model show that the trade-off does not appear to be significant in any of the tested specifications. The results are robust to the introduction of a set of conventional controls related to the labor market. JEL Classification: H53, H55, 138.

Keywords: Social assistance, Minimum income protection, Active labor market policies, European welfare states
\end{abstract}

\section{Introduction}

This paper addresses the relationship between the adequacy of minimum safety-nets and the increased focus on activation strategies in labor market policies in European welfare states. To which extent can the effectiveness of activation policies go hand in hand with offering adequate levels of minimum income protection (MIP, hereafter) and social assistance (SA, hereafter)? On the one hand, do minimum income schemes have to be integrated in the overall activation framework and hence reduced in magnitude in order not to distort work incentives? On the other hand, how to achieve that balance whilst ensuring that minimum income schemes do not end up creating poverty traps? These broad questions lie behind the empirical analysis of the current paper, which aims at testing two opposite working hypotheses on the issue. It has to be pointed out that, instead of taking a normative stand on the balance between activation and out-of-work benefits, the current study aims at showing what has been the actual practice in European welfare states from 1990 to 2013.

Immervoll (2012) has analyzed the policy design and effectiveness of minimum income benefits in OECD countries. Nelson (2013) has explored the question of to which extent social assistance in European welfare states provides protection against low income. On the other hand, a meta-analysis of the literature on activation strategies implemented in labor markets of OECD countries has been provided by Card et al. (2010). The interaction between activation and income support has been

(C) The Author(s). 2017 Open Access This article is distributed under the terms of the Creative Commons Attribution 4.0 International License (http://creativecommons.org/licenses/by/4.0/), which permits unrestricted use, distribution, and reproduction in any medium, provided you give appropriate credit to the original author(s) and the source, provide a link to the Creative Commons license, and indicate if changes were made. 
investigated by Immervoll and Scarpetta (2012), advocating for an effective policy mix based on the right balance between activation, income support, and work incentives. In the economic literature, Besley and Coate (1992) have analyzed this issue by exploring the incentive case for workfare. Their conclusion is that, for there to be a deterrent argument for workfare (i.e., for the benefits for a reduced number of poor exceeding the induced total costs of workfare), the government will have to impose significantly more than a small work requirement. Molander and Torsvik (2015) investigate and analyze from a normative point of view the main arguments justifying implementation of mandatory activation for benefit recipients. The four arguments highlighted and comparatively evaluated are efficiency, sustainability, paternalism, and justice. All these important contributions in the economic and social policy literature provided the ground for the development of the research question of this paper, which is introduced as follows.

A conceptual framework is outlined in the next section in order to frame the two working hypotheses which are subsequently tested in the empirical analysis. The framework is constituted by the "disincentive" view prescribing low out-ofwork benefits parallel to a high expenditure on active labor market policies (ALMPs, hereafter) and by the "generosity" view, which would instead complement the high expenditure on ALMPs with higher benefit levels. Hence, the main research question arises as such: which of these two "views" or working hypotheses are supported by the data on minimum income schemes and expenditure on activation for European welfare states?

The main contributions of the paper are summarized as follows. Firstly, by employing the dataset on benefit levels of SA and minimum income protection (MIP) in 22 European countries in the period 1990-2013, the descriptive empirical analysis indicates a marked reduction as regards the adequacy of income support for inactive lowincome individuals in European welfare states since 1994. This stylized fact, seemingly providing initial support for the "disincentive" view, constitutes the ground for the proceeding of the analysis on the interaction of provision of out-of-work benefits with activation. Second, the paper tests empirically the null hypothesis of the presence of a trade-off between the adequacy of benefit levels and the aggregate expenditure on ALMPs. The empirical analysis posits different specifications of the fixed effects model, in order to guarantee robustness of the results. The results indicate that the trade-off does not appear to be significant, in any of the tested specifications. Whenever significant, the sign of the coefficient indicating a covariation between out-of-work benefits and expenditure on activation is slightly positive. In other words, the "generosity" view seems to receive support from the data, indicating that it is the overall expenditure and degree of generosity of the welfare states that matters. A generous welfare state will provide both high out-of-work benefits and high expenditure on activation, whilst a less generous one will cut on the benefits without investing in activation. These results are proven robust to the introduction of a set of conventional controls related to the labor market.

The paper proceeds as follows. In Section 2, the conceptual framework is outlined. The data and the stylized facts are presented in Section 3, whilst Section 4 describes the empirical analysis. Section 5 presents the results, whilst Section 6 discusses them in light of the conceptual framework. Section 7 concludes. 


\section{Conceptual framework}

This section aims at presenting the conceptual framework which will be empirically tested in the rest of the article. The actual relationship between social assistance and minimum income protection, in general defined as minimum income schemes (MISs, hereafter) or out-of-work benefits, and activation policies is pinned down by government authorities, mainly based on two counteracting considerations.

[1] On one side, the "disincentive" view prescribes that benefits must be kept low not to distort work incentives, so that inactive low-income individuals would take part in activation programs rather than relying on passive benefits. Hence, assuming that the authorities take into account this trade-off for a representative (average) benefit receiver, we should as a result observe a trade-off between benefits and activation at the macro-institutional level as well. Frazer and Marlier (2009) in their overview about the adequacy of MISs across EU member states include a detailed list of the specific disincentives to take up work for inactive individuals. The stylized fact of increased obligations of welfare recipients at the European level, jointly with the erosion of out-of-work benefit levels, has been highlighted as the potential realization of a trade-off between activation and benefits in Nelson (2013) for the period 1990-2007 in 19 European countries. The current paper aims at testing this hypothesis of trade-off against the following alternative hypothesis.

[2] On the other hand, European countries in the last decades aimed at combining a strategy of poverty reduction for individuals who are not working, jointly with promotion of return to employment (OECD, 2005). This joint strategy, which I label as the "generosity" view, would correspond to a policy of maintaining (or even increasing) the current levels of adequacy of income support whilst increasing expenditure on ALMPs. This view is backed-up by Frazer and Marlier (2009), who provide a list of policy-oriented suggestions to EU member states, and precisely address the strategy to avoid disincentive effects whilst at the same time ensuring adequacy of MISs.

Which of these two working hypotheses have prevailed in the actual policy making of the European countries' authorities in the years 1990-2013? In order to give a tentative answer to this empirical question, I turn to the data in the next section.

\section{Data and stylized facts}

At first, the study aims at presenting some stylized facts related to social assistance (SA) and minimum income protection (MIP) benefits in Europe. The dataset utilized in this work is the social assistance and minimum income protection (SAMIP) dataset, which includes detailed comparable information on the benefit levels of individuals receiving income support in a large number of European countries, for the years 19902013. The full SAMIP dataset contains benefit levels for three typical households: a single person, a lone parent, and a two parent family. However, this study focuses exclusively on the single person case, whilst the two other households are excluded due to missing data (for the full period 1990-2013) on mean equivalized income necessary to compute the abovementioned adequacy measures. ${ }^{1}$ 
The SA rates from the SAMIP dataset employed in this study are denominated in local currency, for a single adult person below retirement age and without children, excluding for instance housing costs and other benefits. The MIP levels build on the SA rates, by including housing costs and other benefits. The SA and MIP benefit levels for a total of 22 European countries (Austria, Belgium, Czech Republic, Denmark, Estonia, Finland, France, Germany, Hungary, Ireland, Italy, Luxembourg, Netherlands, Norway, Poland, Portugal, Slovakia, Slovenia, Spain, Sweden, Switzerland, United Kingdom) are then standardized by either GDP per capita or by average annual wages, ${ }^{2}$ providing an internationally comparable proxy of the adequacy or relative "generosity" of out-ofwork benefits in a given country. The main variables in the dataset used for the empirical analysis of this work are summarized in Table 1.

The stylized facts about the series on adequacy of SA and MIP are presented below. Figure 1 shows an overall decreasing tendency for the median adequacy of social assistance in European countries. The turn from a slight upward tendency to a decreasing one takes place around year 1994, from which SA adequacy inevitably declines until year 2005, remaining stable from then onwards.

As shown in Fig. 2, variation across countries appears to be wider for the adequacy of MIP as compared to that of SA. In addition, we observe a tendency towards a lower average and median level for both schemes in 2013 as compared to 1990. In other words, Figs. 1 and 2 indicate that both SA and MIP adequacies have been reduced at the overall European level. The hypothesis that this result has been endogenously driven by contemporaneous growth in GDP per capita is relevant for the countries taken individually, but becomes less plausible at the cross-country level.

Another stylized fact is provided by simply focusing on the 1990-2013 series for the sample variance of SA adequacy for the 22 European countries included in the analysis. Figure 3 plots this time series, computed by using yearly SA rates.

As shown in Fig. 3, after an initial period 1990-2000 with significant jumps in the variance of SA adequacy, the period from 2000 onwards presents an approximately constant level among European countries (a set of standard unit-root tests have been conducted as well, rejecting the unit-root null hypothesis at the 95\% confidence level). This evidence applies to both measures of adequacy, independently of whether the denominator is given by GDP per capita or average annual wages. A thorough empirical analysis of the issue of convergence or divergence as regards the path of SA adequacy

Table 1 Summary statistics for the main variables in the dataset

\begin{tabular}{lccccc}
\hline & Obs. & Mean & Std. dev. & Min & Max \\
\hline SA/GDP per capita & 490 & 0.1905 & 0.0657 & 0.0535 & 0.4344 \\
SA/avg. annual wages & 482 & 0.1797 & 0.0540 & 0.0611 & 0.3414 \\
MIP/GDP per capita & 489 & 0.2707 & 0.0899 & 0.1036 & 0.5054 \\
MIP/avg. annual wages & 482 & 0.2572 & 0.0832 & 0.1066 & 0.5364 \\
ALMP (as \% of GDP) & 467 & 2.0488 & 1.249 & 0.15 & 7.07 \\
Trade union density & 508 & 35.898 & 20.511 & 5.6543 & 83.862 \\
Total employment index & 377 & 94.732 & 11.823 & 52.206 & 146.27 \\
Unemployment (\% of labor force) & 516 & 8.0393 & 4.2666 & 0.4689 & 26.187 \\
\hline
\end{tabular}

Note. Data sources. (1) OECD.Stat (2016) for: GDP per capita at current prices; average annual wages; ALMP as \% of GDP; trade union density; total employment index; unemployment as \% of labor force. (2) SAMIP (2016) dataset for: SA rates; MIP rates 


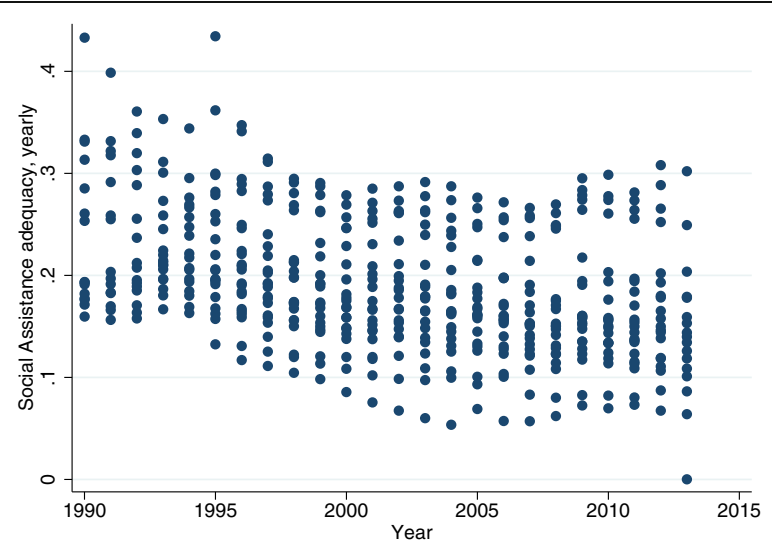

Fig. 1 Social Assistance adequacy, 1990-2013. Note: social assistance (SA) yearly rates standardized by GDP per capita for 22 European countries in the years 1990-2013

among European countries lies outside the scope of this paper. However, it has to be pointed out that Nelson (2008) analyzed trends and levels of minimum income protection in Europe for the period 1990-2005 and his results point in the direction of a converging path.

How does the previous literature explain the decreasing level of adequacy for SA and MIP from around 1994 onwards? Marchal et al. (2016) have highlighted the role of austerity in order to obtain a causal explanation of this retrenchment in the generosity degree of SA and MIP since the 1990s. The current study, rather than revisiting the analysis of the fundamental determinants of out-of-work benefit levels, aims instead at exploring the relationship between adequacy of benefits and activation policies at the cross-country level, as explained in the conceptual framework of the previous section.

Let us turn now to the stylized facts on activation policies, primarily aimed at bringing individuals back to employment. Due to high heterogeneity across countries in the approaches to activation as documented by Escudero (2015) and to the specific research question under analysis, this work focuses on the aggregate value given by countries' public expenditure on ALMPs as a percentage of GDP. Martin John (2014) has

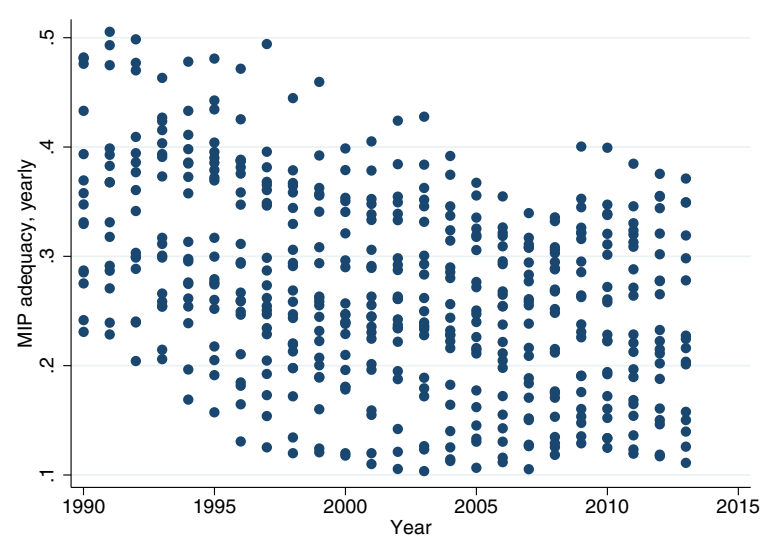

Fig. 2 Minimum income protection adequacy, 1990-2013. Note: minimum income protection (MIP) yearly rates standardized by GDP per capita for 22 European countries in the years 1990-2013 


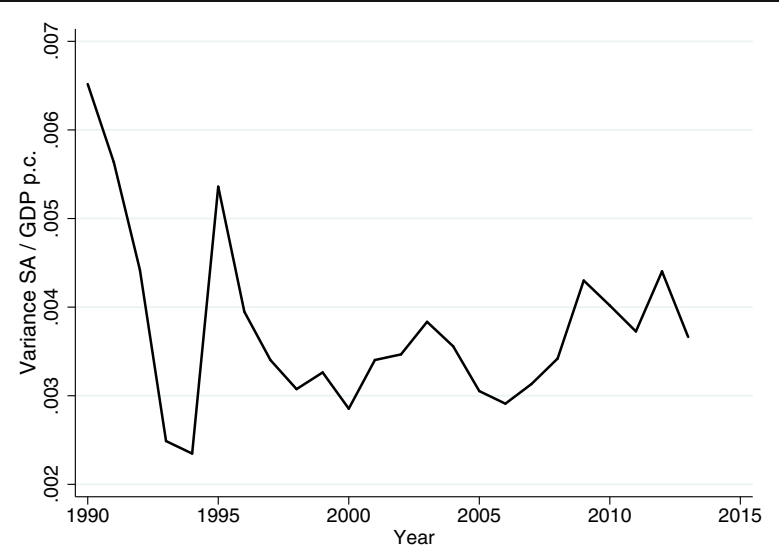

Fig. 3 Sample variance of Social assistance adequacy, 1990-2013

extensively documented the evidence of an increase in public expenditure related to active labor market policies (ALMPs) in European countries in the last decades, also in relation to their effectiveness. The above evidence (Figs. 1 and 2) of decreasing SA and MIP adequacy combined with a sustained public expenditure in ALMPs pins down the research question of this paper, which aims at investigating the validity of the abovementioned working hypotheses based on the "disincentive" or "generosity" views. Let us observe in Fig. 4 the joint scatter plot for both SA and MIP adequacy and the fraction of GDP spent on ALMPs.

Figure 4 points to a somewhat positive relationship between both SA (red) and MIP (blue) adequacy and the fraction of GDP dedicated to ALMPs. The investigation of the actual relationship between these variables will be the main task of the following sections where the empirical analysis is conducted.

\section{Empirical strategy}

The relationships I estimated are represented by the following pair of log-log alternative specifications:

$$
\mathrm{SA}_{j, t}=a_{j}+\beta_{t}+\gamma \mathrm{ALMP}_{j, t}+\theta_{j, t}^{\prime} \varphi+\epsilon_{j, t},
$$

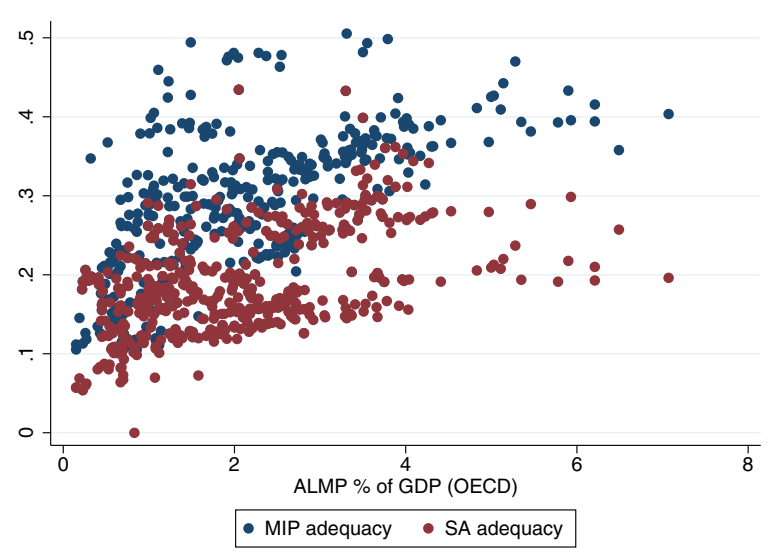

Fig. 4 SA and MIP adequacy and ALMPS, 1990-2013 


$$
\operatorname{MIP}_{j, t}=\delta_{j}+\pi_{t}+\tau \mathrm{ALMP}_{j, t}+\mu_{j, t}^{\prime} \rho+\epsilon_{j, t},
$$

in which $\mathrm{SA}_{j, t}$ in (1) and $\mathrm{MIP}_{j, t}$ in (2) are respectively the log of SA and MIP adequacy variables for country $\mathfrak{j}$, standardized either by GDP per capita or by average annual wages; ${ }^{3} a_{j}$ and $\delta_{j}$ are dummy variables estimating country fixed effects; $\beta_{t}$ and $\pi_{t}$ estimate time fixed effects; $\mathrm{ALMP}_{j, t}$ represents the log of the fraction of GDP invested in active labor market policies for country j; $\theta_{j, t}^{\prime}$ and $\mu_{j, t}^{\prime}$ include a set of conventional covariates related to labor market institutions (trade union density, total employment, unemployment as a $\%$ of the labor force); and $\epsilon_{j, t}$ are error terms adjusted for country clustering.

As regards the choice of the specific control variables, trade union density (TUD, hereafter) has been included based on the following logic. Assume for instance that the results indicate a trade-off between out-of-work benefits and ALMPs so to confirm the "disincentive" view. The expected positive effect of higher TUD on the wages for the low-skilled labor force would potentially make out-of-work benefits relatively less appealing for these workers, hence contributing to mitigate the significance and robustness of the trade-off with activation policies.

For each of the two adequacy measures, models (1) and (2) were estimated at first by pooled OLS with standard errors clustered by countries. Subsequently, the dummy variables estimating country and time fixed effects were introduced. At last, in order to take into account as well for the hypothesis of autocorrelation in the idiosyncratic error terms, (1) and (2) were estimated in the presence of AR (1) disturbance.

A remark about endogeneity issues has to be done here. Given the specifications of (1) and (2) and the policy variables at hand, the risk of endogeneity does not allow to exclude the presence of reverse causality at this stage. However, this does not need to fully invalidate the research question of the current study. On one side, results indicating weak significance for the effect of ALMPs on SA/MIP would for instance give evidence in the direction of disregarding the "disincentive" view mentioned above, since that hypothesis requires a strongly significant inverse relationship to be confirmed. On the other hand, in case of positive and significant relationship between SA/MIP adequacy and ALMPs, the evidence would lead to a preference for the "generosity" view, regardless of the underlying direction of causality. In other words, the aim of the current exploratory study is to open the field for future research on this specific relationship, which should also be supported by analyses at the within-country level for which a more powerful identification strategy and a higher level of detail can be obtained. The results of the different estimations are presented in the next section.

\section{Econometric results}

Tables 2, 3, 4, and 5 below report the effects of the expenditure of ALMPs on the SA and MIP adequacy variables as specified by (1) and (2) and estimated by pooled OLS with clustered standard errors, for each of the two standardizations (either GDP per capita in Tables 2 and 3 or average annual wages in Tables 4 and 5).

The OLS coefficients in Tables 2, 3, 4, and 5 are elasticities; hence, they show the expected percentage change for SA/MIP adequacy when the fraction of GDP devoted to ALMPs increases by $1 \%$. A first look at these introductory results indicate that ALMPs have a positive and significant effect on both SA and MIP adequacy, with the latter being strongly significant when all controls are included as well. The magnitude of the 
Table 2 Log-log model estimated by pooled OLS with clustered standard errors

\begin{tabular}{lllll}
\hline & $(1)$ & $(2)$ & $(3)$ & $(4)$ \\
& SAGDP & SAGDP & SAGDP & SAGDP \\
\hline ALMP (\% of GDP) & $0.253^{* * *}$ & $0.207^{* * *}$ & $0.149^{* *}$ & 0.0915 \\
& $(0.0687)$ & $(0.0545)$ & $(0.0560)$ & $(0.102)$ \\
Trade union density & & $0.393^{* * *}$ & $0.348^{*}$ & $0.360^{*}$ \\
& & $(0.0977)$ & $(0.142)$ & $(0.147)$ \\
Total employment & & -0.399 & -0.384 \\
& & & $(0.236)$ & $(0.227)$ \\
Unemployment (\% of LF) & & & 0.0778 \\
& & & & $(0.0946)$ \\
Obs. & 445 & 440 & & 318 \\
\hline Clustered standard errors in parentheses, ${ }^{*} p<0.05,{ }^{* * *} p<0.01,{ }^{* * * *} p<0.001$ & &
\end{tabular}

effect does not overcome the $0.3 \%$ of the initial adequacy rates (in other words, an elasticity of 0.3). As predicted in the previous section, the introduction of TUD as a control has the effect of reducing the impact of ALMPs on adequacy rates, indicating that the relationship becomes milder with higher wages for the low-skilled individuals.

These results might be biased by time-invariant and country-specific factors simultaneously affecting the dependent variable and the regressors. Hence, we move to the fixed effects (FE, hereafter) model specification which controls for all the acrosscountry action, in order to exploit the within-country variation over time.

Tables 6, 7, 8, and 9 below report now the effects of the expenditure of ALMPs on the SA/MIP adequacy variables as estimated by the FE model, for each of the two standardizations (either GDP per capita in Tables 6 and 7 or average annual wages in Tables 8 and 9).

The FE results of the above Tables $6,7,8$, and 9 indicate that, mostly for the case of the SA adequacy (under both the possible standardizations), the significance of the pooled OLS coefficients was due to some unobservable time-invariant and country specific variable, which has been now taken away by the FE dummies. When it comes to the MIP adequacy, the effects of ALMPs are slightly less significant, however mostly of the same magnitude as in the simpler pooled OLS models. Notice that, until now, none

Table 3 Log-log model estimated by pooled OLS with clustered standard errors

\begin{tabular}{lllll}
\hline & $(1)$ & $(2)$ & $(3)$ & $(4)$ \\
& MIPGDP & MIPGDP & MIPGDP & MIPGDP \\
\hline ALMP (\% of GDP) & $0.294^{* * *}$ & $0.262^{* * * *}$ & $0.239^{* * *}$ & $0.189^{* * *}$ \\
& $(0.0548)$ & $(0.0436)$ & $(0.0393)$ & $(0.0405)$ \\
Trade union density & & $0.237^{* * *}$ & $0.216^{*}$ & $0.223^{* * *}$ \\
& & $(0.0786)$ & $(0.0843)$ & $(0.0839)$ \\
Total employment & & -0.402 & -0.392 \\
& & & $(0.217)$ & $(0.202)$ \\
Unemployment (\% of LF) & & & 0.0671 \\
& 445 & 440 & 318 & $(0.0565)$ \\
Obs. & & & 318 \\
\hline Clustered standard errors in parentheses, ${ }^{*} p<0.05,{ }^{* *} p<0.01,{ }^{* * * *} p<0.001$ &
\end{tabular}


Table 4 Log-log model estimated by pooled OLS with clustered standard errors

\begin{tabular}{lllll}
\hline & $(1)$ & $(2)$ & $(3)$ & $(4)$ \\
& SAW & SAW & SAW & SAW \\
\hline ALMP (\% of GDP) & 0.113 & 0.0813 & 0.0505 & 0.0153 \\
& $(0.0587)$ & $(0.0540)$ & $(0.0542)$ & $(0.113)$ \\
Trade union density & & $0.304^{* *}$ & 0.307 & 0.313 \\
& & $(0.111)$ & $(0.167)$ & $(0.173)$ \\
Total employment & & 0.185 & 0.193 \\
& & & $(0.237)$ & $(0.235)$ \\
Unemployment (\% of LF) & & & 0.0483 \\
& 438 & & & $(0.102)$ \\
Obs. & & & 315 & 315 \\
\hline
\end{tabular}

Clustered standard errors in parentheses, ${ }^{* *} p<0.01$

of the above eight specifications entails a trade-off between ALMPs and SA/MIP adequacy measures.

At last, in order to take into account the possibility of serial correlation in the error terms which would determine inconsistency and biasness of both the OLS and the FE models, a last set of regressions has been conducted by assuming a AR (1) disturbance term, in addition to country and time FE. Tables 10, 11, 12, and 13 below report the results of these regressions.

The results of these last Tables 10,11,12, and 13 can be summarized as follows. The effects of ALMPs on SA and MIP adequacy variables are now strongly significant, however only for the standardization with respect to GDP per capita (Tables 10 and 11). The magnitude of the effect has been now reduced though, to a maximum level of $0.169 \%$ increase in adequacy. The effects on adequacy measures shown in Tables 12 and 13 appear instead not to be significant, in contradiction to the previous FE results of Tables 8 and 9. A thorough discussion of these results is provided in the next section.

\section{Discussion}

This section aims at interpreting the results of the empirical analysis in light of the conceptual framework outlined at the beginning of this paper. The econometric results

Table 5 Log-log model estimated by pooled OLS with clustered standard errors

\begin{tabular}{lllll}
\hline & $(1)$ & $(2)$ & $(3)$ & $(4)$ \\
& MIPW & MIPW & MIPW & MIPW \\
\hline ALMP (\% of GDP) & $0.147^{* * *}$ & $0.134^{* * *}$ & $0.139^{* * * *}$ & $0.109^{* *}$ \\
& $(0.0361)$ & $(0.0318)$ & $(0.0268)$ & $(0.0401)$ \\
Trade union density & & 0.134 & 0.159 & 0.164 \\
& & $(0.0687)$ & $(0.0920)$ & $(0.0914)$ \\
Total employment & & 0.172 & 0.179 \\
& & & $(0.216)$ & $(0.207)$ \\
Unemployment (\% of LF) & & & 0.0398 \\
& & & & $(0.0525)$ \\
Obs. & 438 & 315 & 315 \\
\hline Clustered standard errors in parentheses, ${ }^{* *} p<0.01,{ }^{* * *} p<0.001$ & &
\end{tabular}


Table 6 Log-log model with country and time fixed effects

\begin{tabular}{lllll}
\hline & $(1)$ & $(2)$ & $(3)$ & $(4)$ \\
& SAGDP & SAGDP & SAGDP & SAGDP \\
\hline ALMP (\% of GDP) & 0.141 & $0.156^{*}$ & $0.120^{*}$ & 0.0139 \\
& $(0.0720)$ & $(0.0567)$ & $(0.0470)$ & $(0.124)$ \\
Trade union density & & 0.216 & 0.297 & 0.265 \\
& & $(0.120)$ & $(0.195)$ & $(0.182)$ \\
Total employment & & -0.227 & -0.139 \\
& & & $(0.299)$ & $(0.330)$ \\
Unemployment (\% of LF) & & & 0.136 \\
& & & & $(0.132)$ \\
Country FE & Yes & Yes & Yes & Yes \\
Time FE & Yes & Yes & Yes & Yes \\
$R^{2}$ & 0.435 & 0.454 & 0.402 & 0.423 \\
Obs. & 445 & 440 & 318 & 318 \\
\hline Clustered standard errors in parentheses, ${ }^{*} p<0.05$ & & &
\end{tabular}

provide a strong evidence of 0 out of 12 model specifications estimating a significant trade-off (i.e., a negative coefficient) between out-of-work benefits and activation. Hence, the results point in the direction of rejecting the "disincentive" view (highlighted in Nelson, 2013) formulated in the conceptual framework. In other words, the results seem to disregard the hypothesis that policy makers in European welfare states have designed MISs precisely in order to avoid the potential trade-off with activation strategies. The robustness of this result to alternative model specifications and across adequacy measures provides an important evidence to take into account in future empirical research of the issue at the cross-country level and a fruitful starting point for causal empirical analyses at the within-country level.

Secondly, it has to be pointed out that, whenever significant, the effects of ALMPs on SA/MIP adequacy (or vice versa, due to reverse causality) are positive regardless of the

Table 7 Log-log model with country and time fixed effects

\begin{tabular}{lllll}
\hline & $(1)$ & $(2)$ & $(3)$ & $(4)$ \\
& MIPGDP & MIPGDP & MIPGDP & MIPGDP \\
\hline ALMP (\% of GDP) & $0.225^{* * *}$ & $0.224^{* * * *}$ & $0.229^{* * *}$ & $0.140^{*}$ \\
Trade union density & $(0.0508)$ & $(0.0511)$ & $(0.0548)$ & $(0.0517)$ \\
& & 0.0478 & 0.166 & 0.140 \\
Total employment & & $(0.130)$ & $(0.155)$ & $(0.163)$ \\
& & & -0.248 & -0.175 \\
Unemployment (\% of LF) & & & $(0.166)$ & $(0.131)$ \\
& & & 0.114 \\
Country FE & & & $(0.0570)$ \\
Time FE & Yes & Yes & Yes & Yes \\
$R^{2}$ & Yes & Yes & Yes & Yes \\
Obs. & 0.516 & 0.502 & 0.563 & 0.583 \\
\hline
\end{tabular}

Clustered standard errors in parentheses, ${ }^{*} p<0.05,{ }^{* * *} p<0.001$ 
Table 8 Log-log model with country and time fixed effects

\begin{tabular}{lllll}
\hline & $(1)$ & $(2)$ & $(3)$ & $(4)$ \\
& SAW & SAW & SAW & SAW \\
\hline ALMP (\% of GDP) & 0.0727 & 0.0838 & 0.0497 & -0.0441 \\
& $(0.0709)$ & $(0.0572)$ & $(0.0454)$ & $(0.135)$ \\
Trade union density & & 0.244 & 0.208 & 0.171 \\
& & $(0.129)$ & $(0.236)$ & $(0.210)$ \\
Total employment & & 0.338 & 0.415 \\
& & & $(0.283)$ & $(0.319)$ \\
Unemployment (\% of LF) & & & & 0.119 \\
& & & & $(0.134)$ \\
Country FE & Yes & Yes & Yes \\
Time FE & Yes & Yes & Yes & Yes \\
$R^{2}$ & 0.190 & 0.238 & 0.165 & 0.189 \\
Obs. & 438 & 437 & 315 & 315 \\
\hline
\end{tabular}

Clustered standard errors in parentheses

model specification (although the magnitude is not large). In other words, this pattern points in the direction of supporting the alternative "generosity" view. Increased expenditure on ALMPs in European welfare states has gone (for some countries) hand in hand with a sustained level of adequacy of minimum income protection and social assistance. A possible interpretation of this evidence goes as follows: it is the overall generosity of the welfare state expenditure that matters. This means that generous welfare states do offer both sustained out-of-work benefit levels, in addition to investing larger fractions of the GDP in activation and reintegration strategies for the inactive individuals. On the other hand, smaller welfare states with a lower degree of overall generosity (measured for instance by the total fraction of GDP devoted to social insurance, activation, and out-ofwork benefits) would cut on the adequacy of benefits, whilst at the same time not considering ALMPs as an alternative option. The next section contains the concluding remarks.

Table 9 Log-log model with country and time fixed effects

\begin{tabular}{lllll}
\hline & $(1)$ & $(2)$ & $(3)$ & $(4)$ \\
& MIPW & MIPW & MIPW & MIPW \\
\hline ALMP (\% of GDP) & $0.145^{* *}$ & $0.148^{* *}$ & $0.153^{* *}$ & 0.0743 \\
Trade union density & $(0.0496)$ & $(0.0478)$ & $(0.0444)$ & $(0.0518)$ \\
& & 0.0610 & 0.0623 & 0.0314 \\
Total employment & & $(0.0998)$ & $(0.162)$ & $(0.163)$ \\
& & & 0.314 & $0.378^{* *}$ \\
Unemployment (\% of LF) & & & $(0.149)$ & $(0.122)$ \\
& & & & 0.0999 \\
Country FE & Yes & Yes & & $(0.0517)$ \\
Time FE & Yes & Yes & Yes & Yes \\
$R^{2}$ & 0.252 & 0.257 & Yes & Yes \\
Obs. & 438 & 437 & 0.258 & 0.288 \\
\hline
\end{tabular}

Clustered standard errors in parentheses, ${ }^{* *} p<0.01$ 
Table 10 Log-log model with AR (1) disturbance, fixed effects

\begin{tabular}{lllll}
\hline & $(1)$ & $(2)$ & $(3)$ & $(4)$ \\
& SAGDP & SAGDP & SAGDP & SAGDP \\
\hline ALMP (\% of GDP) & $0.136^{* * *}$ & $0.169^{* * *}$ & $0.137^{* * *}$ & $0.0901^{* *}$ \\
& $(0.0227)$ & $(0.0219)$ & $(0.0263)$ & $(0.0332)$ \\
Trade union density & & $-0.375^{* * *}$ & -0.151 & $-0.223^{*}$ \\
& & $(0.0659)$ & $(0.0976)$ & $(0.104)$ \\
Total employment & & $-0.335^{* * *}$ & $-0.276^{* *}$ \\
& & & $(0.0863)$ & $(0.0906)$ \\
Unemployment (\% of LF) & & & $0.0762^{*}$ \\
& & & & $(0.0377)$ \\
Country FE & & Yes & Yes & Yes \\
Time FE & Yes & Yes & Yes & Yes \\
Obs. & 418 & 302 & 302 \\
\hline
\end{tabular}

Clustered standard errors in parentheses, ${ }^{*} p<0.05,{ }^{* *} p<0.01,{ }^{* * *} p<0.001$

\section{Conclusions}

The main theme of this study was to investigate the actual shape of the relationship between the adequacy of minimum safety nets and the aggregate expenditure on activation strategies in labor market policies of European welfare states. Rather than exploring this relationship at the normative level or at the microeconomic theoretical level, the approach has been that of investigating the actual practice of authorities in European welfare states in the period 1990-2013. At first, a conceptual framework outlined the two competing working hypotheses, labeled as the "disincentive" and the "generosity" views. The former prescribes a trade-off between the level of out-of-work benefits and activation, in order to increase efficacy of ALMPs when it comes to reintegrating inactive individuals into the labor force. The latter works instead by allowing a joint strategy of sustained level of adequacy of income support whilst at the same time increased government expenditure on activation strategies. The SAMIP dataset provided the yearly rates of SA and MIP

Table 11 Log-log model with AR (1) disturbance, fixed effects

\begin{tabular}{lllll}
\hline & $(1)$ & $(2)$ & $(3)$ & $(4)$ \\
& MIPGDP & MIPGDP & MIPGDP & MIPGDP \\
\hline ALMP (\% of GDP) & $0.146^{* * *}$ & $0.166^{* * *}$ & $0.141^{* * * *}$ & $0.0982^{* * *}$ \\
& $(0.0210)$ & $(0.0203)$ & $(0.0216)$ & $(0.0275)$ \\
Trade union density & & $-0.225^{* * *}$ & -0.0534 & -0.119 \\
& & $(0.0552)$ & $(0.0768)$ & $(0.0805)$ \\
Total employment & & $-0.233^{* * *}$ & $-0.187^{* *}$ \\
& & & $(0.0670)$ & $(0.0689)$ \\
Unemployment (\% of LF) & & & $0.0762^{*}$ \\
& & & & $0.0308)$ \\
Country FE & & Yes & Yes & Yes \\
Time FE & Yes & Yes & Yes & Yes \\
Obs. & 423 & 418 & 302 & 302 \\
\hline
\end{tabular}

Clustered standard errors in parentheses, ${ }^{*} p<0.05,{ }^{* *} p<0.01,{ }^{* * *} p<0.001$ 
Table 12 Log-log model with AR (1) disturbance, fixed effects

\begin{tabular}{lllll}
\hline & $(1)$ & $(2)$ & $(3)$ & $(4)$ \\
& SAW & SAW & SAW & SAW \\
\hline ALMP (\% of GDP) & 0.0290 & $0.0571^{* *}$ & 0.0250 & 0.0156 \\
& $(0.0191)$ & $(0.0187)$ & $(0.0268)$ & $(0.0341)$ \\
Trade union density & & $-0.412^{* * *}$ & $-0.290^{* *}$ & $-0.306^{* *}$ \\
& & $(0.0602)$ & $(0.0975)$ & $(0.104)$ \\
Total employment & & $-0.225^{*}$ & $-0.213^{*}$ \\
& & & $(0.0874)$ & $(0.0919)$ \\
Unemployment (\% of LF) & & & & 0.0167 \\
& & & & $(0.0378)$ \\
Country FE & & Yes & Yes & Yes \\
Time FE & Yes & Yes & Yes & Yes \\
Obs. & Yes & 415 & 299 & 299 \\
\hline
\end{tabular}

Clustered standard errors in parentheses, ${ }^{*} p<0.05,{ }^{* *} p<0.01,{ }^{* * *} p<0.001$

employed in order to construct the series of adequacy of minimum income schemes for up to 22 European welfare states. Although the cross-country empirical analysis conducted in this study cannot exclude the possibilities of reverse causality, the results provide unambiguous evidence so to disregard the "disincentive" hypothesis. More precisely, the results indicate that, whenever significant, the effect of increased expenditure on ALMPs does not imply parallel cuts in the adequacy of minimum income schemes. Future research is needed to investigate the research questions that lies ahead of this study. First, a natural follow-up would be to provide within-country analyses of the trade-off between the two working hypotheses analyzed here, in order to complement the current study. In particular, is it the overall generosity and aggregate expenditure of the European welfare states that can close the puzzle by explaining both the direction of causalities behind the results of this study? Further, can we assume that more generous welfare states provide both a higher level of out-of-benefits and a higher aggregate expenditure on

Table 13 Log-log model with AR (1) disturbance, fixed effects

\begin{tabular}{lllll}
\hline & $(1)$ & $(2)$ & $(3)$ & $(4)$ \\
& MIPW & MIPW & MIPW & MIPW \\
\hline ALMP (\% of GDP) & $0.0388^{*}$ & $0.0553^{* *}$ & 0.0371 & 0.0287 \\
& $(0.0172)$ & $(0.0168)$ & $(0.0219)$ & $(0.0284)$ \\
Trade union density & & $-0.263^{* * *}$ & $-0.198^{* *}$ & $-0.210^{* *}$ \\
& & $(0.0455)$ & $(0.0751)$ & $(0.0791)$ \\
Total employment & & -0.119 & -0.112 \\
& & & $(0.0654)$ & $(0.0673)$ \\
Unemployment (\% of LF) & & & 0.0144 \\
& & & & $(0.0309)$ \\
Country FE & & Yes & Yes & Yes \\
Time FE & Yes & Yes & Yes & Yes \\
Obs. & Yes & 415 & 299 & 299 \\
\hline
\end{tabular}

Clustered standard errors in parentheses, ${ }^{*} p<0.05,{ }^{* *} p<0.01,{ }^{* * *} p<0.001$ 
activation strategies? On the other hand, small welfare states would pin down less generous minimum income schemes, whilst at the same time cutting on the expenses related to reintegration of inactive individuals in the labor force.

\section{Endnotes}

${ }^{1}$ For instance, EU-SILC data on mean equivalized income before social transfers by household type are available only from 2003 onwards (and for some countries even later). Hence, dividing SA and MIP rates for the other two household types available in the SAMIP dataset by the EU-SILC mean equivalized incomes would allow only to investigate the period 2003-2013, which would imply a much smaller sample.

${ }^{2}$ I will provide information or plots about both series whenever the measures of adequacy differ substantially. Otherwise, the default adequacy measure is the one which standardizes SA rates by GDP per capita. The full dataset and .do file producing results for both measures of adequacy is available from the author upon request.

${ }^{3} \mathrm{Im}$-Pesaran-Shin unit-root test has been conducted for each of these four series before taking logs, in order to test for stationarity. None of these four tests indicated the presence of unit roots for all panels.

\section{Additional file}

Additional file 1: Dataset in .xlsx format. (XLSX 99 kb)

\section{Acknowledgements}

I am grateful for comments from two anonymous referees and the editor, Veronica Escudero, Johannes Mauritzen, Nicholas Sheard, and Malin Jørgine Fævelen. The empirical analyses of this work are based on data from the social assistance and minimum income protection dataset (SAMIP), provided as part of the social policy indicator database (SPIN). The usual disclaimer applies.

Responsible editor: Martin Kahanec

Availability of data and materials

The dataset supporting the conclusions of this article is provided as Additional file 1.

\section{Competing interests}

The IZA Journal of European Labor Studies is committed to the IZA Guiding Principles of Research Integrity. The author declares that he has observed these principles.

Received: 25 October 2016 Accepted: 13 December 2016

Published online: 13 January 2017

\section{References}

Besley T, Coate S (1992) Workfare versus welfare: incentive arguments for work requirements in poverty alleviation programs. Am Econ Rev 82(1):249-261

Card D, Kluve J, Weber A (2010) Active labour market policy evaluations: a meta-analysis. Econ J 120:F452-F477. doi:10.1111/j.1468-0297.2010.02387.x

Escudero V. (2015) Are active labour market policies effective in activating and integrating low-skilled individuals? An international comparison. PSE Working Papers halshs-01105347, HAL

Frazer H, Marlier E (2009) Minimum income schemes across EU member states. Synthesis Report. CEPS/INSTEAD, Luxembourg Immervoll H. (2012) Minimum-income benefits in OECD countries: policy design, effectiveness and challenges. In D. J. Besharov, K. A. Couch (eds.) Counting the Poor: New Thinking About European Poverty Measures and Lessons for the United States. Oxford: Oxford University Press, 171-209

Immervoll H, Scarpetta S (2012) Activation and employment support policies in OECD countries. An overview of current approaches. IZA J Labor Policy 1:9

Marchal S, Marx I, Van Mechelen N (2016) Minimum income protection in the austerity tide. IZA J Eur Labor Stud 5:4. doi:10.1186/s40174-016-0052-7

Martin John P (2014) Activation and active labour market policies in OECD countries: stylized facts and evidence on their effectiveness. IZA Policy Paper No. 84, June. doi:10.1186/2193-9004-1-9

Molander A, Torsvik G (2015) Getting people into work: what (if anything) can justify mandatory activation of welfare recipients? J Appl Philos. doi:10.1111/japp.12132 
Nelson K (2008) Minimum income protection and European integration: trends and levels of minimum benefits in comparative perspective, 1990-2005. Int J Health Serv 38(1):103-124

Nelson K (2013) Social assistance and EU poverty thresholds 1990-2008. Are European welfare systems providing just and fair protection against low income? Eur Sociol Rev 29(2):386-401. doi:10.1093/esr/jcr080e

OECD (2005) Increasing financial incentives to work: the role of in-work benefits. OECD Employment Outlook. Paris https://www.oecd.org/els/emp/36780865.pdf. Accessed 20 Sept 2016

OECD.Stat (2016) http://stats.oecd.org/. Accessed 24 Sept 2016

SAMIP (2016) http//www.sofi.su.se/spin/. Accessed 20 Sept 2016

Submit your manuscript to a SpringerOpen ${ }^{\circ}$ journal and benefit from:

- Convenient online submission

- Rigorous peer review

- Immediate publication on acceptance

- Open access: articles freely available online

- High visibility within the field

- Retaining the copyright to your article

Submit your next manuscript at $>$ springeropen.com 